JIOM Nepal, Volume 41, Number 2, August 2019, page 30-34

\title{
Outcome Analysis of Lipomeningomyelocele Repair in Children in a Tertiary Care Center in Nepal
}

\author{
Puspa R Koirala, Amit B Pradhanang, Gopal Sedain, Mohan R Sharma \\ Department of Neurosurgery, Maharajgunj Medical Campus, Tribhuvan University Teaching Hospital, Kathmandu, \\ Nepal
}

\section{Corresponding author:}

Puspa R Koirala, MBBS, MS

Department of Neurosurgery, Maharajgunj Medical Campus, Tribhuvan University Teaching Hospital, Kathmandu, Nepal

Email: pussparajkoirala@gmail.com

Submitted: May 6, 2019

Accepted : Jul 23, 2019

\begin{abstract}
Introduction

Lipomeningomyelocele (LMM) is a common neural tube defect especially prevalent in low income countries. When they get appropriate care, long term result is generally good provided the patient receives good neurosurgical, paediatric and rehabilitation care. Surgery is the mainstay of treatment. Our aim was to analyze immediate and long-term results of lipomeningomyelocele repair in symptomatic patients presenting to TU Teaching Hospital, Kathmandu, Nepal.

\section{Methods}

Thirteen patients admitted to Department of Neurosurgery from January 2017 to December 2018 were evaluated. All patients underwent MRI of whole spine before surgery. Surgical procedures involved total excision of lipoma and repair in 10 patients and subtotal excision and repair in 3 patients. Division of filum terminale could be done in 8 patients. Follow up varied from 6 months to 2 years.

\section{Results}

This study included 8(61.5 \%) patients of lumbosacral LMM, 3(23\%) patients of sacral LMM and 2( 15.38\%) patients of thoracolumbar LMM . About 2 (15.38\%) were operated before 3 months of age, $2(15.38 \%)$ were operated between 3-6 months of age, 5 (38.46\%) were operated between 6-12 months of age and 4 (30.7\%) were operated after 1 year. All children except one presented with lump on back since birth and four presented with urinary incontinence, one presented with bilateral club foot. Four (30.7\%) patients had weakness of one or both lower limbs. Two (15.38\%) patients had improvement in urinary incontinence, two unchanged and one had developed urinary incontinence postoperatively. Four children with had weakness of lower limbs; one patient improved whereas three patients did not improve postoperatively. There was no development of postoperative hydrocephalus after LMM repair. Three (23\%) patients developed wound infection who responded well with regular dressings and antibiotics.
\end{abstract}

\section{Conclusion}

Lipomeningomyelocele repair can be done with satisfactory outcome with total excision of lipoma and division of filum terminale. Patients with residual lipoma and undivided filum terminale should be observed closely for the development of progressive neurological deterioration.

Keywords: Lipoma, lipomeningomyelocele, neurosurgery, outcome

\section{INTRODUCTION}

ipomeningomyelocele (LMM) is a form of closed neural tube defect. It is a complex disorder that may present with neurological deficits secondary to the inherent tethered cord. Treatment strategies aim to remove adipose tissue, identify defect in the lumbosacral fascia for the release of the tethering, possible release of the filum terminale, preservation of neural elements, and prevention of retethering of the spinal cord
Traditionally, spinal lipomas have been classified into three groups based on location of neural placode lipoma junction, dorsal, caudal and terminal, known as the Chapman classification.1,2 In dorsal spinal lipomas, the junction is on the dorsal aspect of the lumbar spinal cord and spares the conus medullaris. The dorsal root entry zone (DREZ) and neural elements are displaced lateral and ventrolateral to the placode -lipoma junction, respectively. The nerve roots emerge from the spinal cord tissue anterior 
Table 1. Type of LMM and age at operation

\begin{tabular}{|c|c|c|c|c|c|}
\hline \multirow{2}{*}{ Type of LMM } & \multirow{2}{*}{$\begin{array}{c}\text { Total number of } \\
\text { patients }\end{array}$} & \multicolumn{4}{|c|}{ Age at operation } \\
\hline & & $<3$ months & 3-6 months & 6-12 months & $>12$ months \\
\hline Lumbosacral & $8(61.53 \%)$ & 1 & 1 & 3 & 3 \\
\hline Sacral & $3(23.07 \%)$ & 0 & 0 & 1 & 2 \\
\hline Lumbar & $2(15.38 \%)$ & 0 & 0 & 1 & 1 \\
\hline
\end{tabular}

to the junctional zone, where the lipoma, dura and conus medullaris converge. In contrast, the conus is involved with caudal lipomas, and neural elements are located rostral to the junction. In caudal lipomas, the fatty tissue can extend from within the central canal caudally, where the fat is intermixed with the nerve roots. Transitional lipomas have a characteristics of both dorsal and caudal types, with viable nerve roots passing through the lipoma tissue. These lesions tend to be assymetric, with a rotational component on the spinal cord. The placode -lipoma junction is thus typically rotated. Pang et al described a chaotic type, which has an irregular border between the placode and lipoma. Fat extends around the spinal cord and on its ventral aspect, obscuring the DREZ. Most LMMs are of the dorsal or transitional type. ${ }^{3}$

Several factors are thought to affect the treatment outcome of LMMs. Age, gender, morphology, the presence and severity of neurological symptoms and absence or presence of an associated spinal cord syrinx are all taken into consideration. Of these morphology is considered the most crucial factor affecting the outcome. For example, transitional lipomas appear to have a higher rate of retethering after surgery than dorsal and caudal types.

\section{METHODS}

This study is a retrospective prospective study. The duration of the study was 2 years (January 2017- December 2018). The study population was children up to the age of 16 years. The study site was Department of Neurosurgery, TUTH, Kathmandu, Nepal.

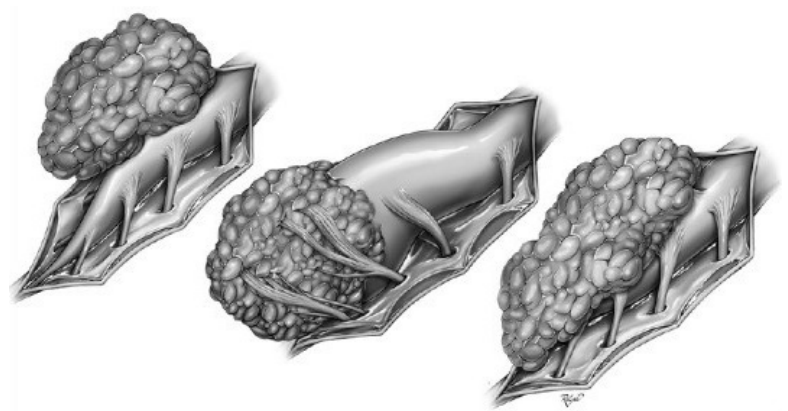

Figure 1. Chapman classification of spinal lipoma: dorsal, terminal, dorsolateral. (Reproduced with permission)

\section{RESULTS}

Thirteen patients admitted to Department of Neurosurgery over a period of one year (January 2017 to December 2018) were evaluated preoperatively by $\mathrm{MRI}$ of whole spine. The age ranges from 2.5 months - 11 years. There were 7 (53.84 \%)boys and $6(46.15 \%)$ girls. Two children operated within 3 months, two operated within 3-6 months, five children operated between 6-12 months, and four children operated after 1 year.

Twelve patient had lump in back, one patient had lump along with skin dimple (figure 1), one had lump with reddish to pinkish patch on the lump. Eight patients had no weakness in bilateral lower limbs. Lower limbs power was assessed preoperatively and postoperatively. Anocutaneous and bulbocavernosus reflexes and anal tone were examined preoperatively and postoperatively in all patients. Head circumference, bladder and bowel function were assessed preoperatively and compared with postoperative findings. MRI of spine and head was done in all patients with swelling over the back.

Patients were operated in prone position under general anesthesia. Incision made were either vertical or horizontal around the lump. Skin flaps were raised in the subcutaneous plane. Dissection was done all around the central lipomatous component. Dura was opened cranially and caudally from the site of defect and intradural component of lipoma was excised (figure 3 ). Detethering of cord was done. Laminotomy was done when felt required. Filum terminale was identified and divided at its lowermost visible end. Dura was closed with Vicryl 4,0 followed by closure of lumbosacral or thoracolumbar fascia over it using Vicryl 4,0. Average operative time was 120 minutes and average blood loss was $30 \mathrm{ml}$. In doubtful cases,

Table 2. Malformations associated with lipomeningomyelocele

\begin{tabular}{lc}
\hline \multicolumn{1}{c}{ Malformations } & Number \\
\hline Low lying cord & $12(92.3 \%)$ \\
Hydrocephalus & $1(7.69 \%)$ \\
Bilateral club foot & $1(7.69 \%)$ \\
Lump & $12(92.3 \%)$ \\
Hydroureteronephrosis & $1(7.69 \%)$ \\
\hline
\end{tabular}


Table 3. Post-operative outcome

\begin{tabular}{lcccc}
\hline \multicolumn{1}{c}{ Functions } & Total patients & Improvement & Deterioration & No change \\
\hline Lower limb power & 4 & 1 & 1 & 11 \\
Lower limb sensations & 2 & - & 1 & 12 \\
Bladder / bowel functions & 4 & 2 & 1 & 10 \\
Higher neurological functions & - & - & - & 13 \\
Wound infection & 3 & - & - \\
\hline
\end{tabular}

neuromonitoring was used to differentiate neural tissue from connective tissue and sharp dissection with scissors was preferred. Drain was not kept in any of the cases. Sutures were removed after 8-10 days and patient was followed regularly.

Seven patients (53.9\%) had dorsal lipoma, three $(23 \%)$ had terminal lipoma and three (23\%) had dorsolateral lipoma.

Three patients had urinary incontinence preoperatively. Two patients had no urinary incontinence after surgery, one patient had transient urinary incontinence which resolved in about 12 days. Two patients had permanent urinary incontinence in 1-2 years of follow up. None of the patients had bowel dysfunction. Four (33.33\%) patients had lower limb weakness before surgery, one patient had improvement in power after surgery, one patient had increased weakness and two patients improved after surgery. All the patients with lower limb weakness were managed by regular physiotherapy. Three patients have superficial surgical site infection. They were managed by daily dressing with mupirocin ointment and oral antibiotics. Perioperative period was otherwise uneventful.

Patients were followed up monthly initially for 6 months, and later follow-up varied according to patient profile. Patients were examined for any increase in head size to detect the development of hydrocephalus. Lower limb power and sensations were assessed by clinical examination.

\section{DISCUSSION}

Lipomeningomyelocele is a neural tube defect in which neural elements are incorporated into a spinal lipoma. This is an uncommon defect occurring in 3-6 patients per 100,000 live births. ${ }^{4}$ Clinical decisionmaking regarding treatment is complicated by the varied pathology and the spectrum of presentations. Embryological abnormalities during primary neurulation account for closed spinal dysraphism. Spinal dysraphism that arises from premature separation of epithelial ectoderm from the neural ectoderm (process called disjunction) result in fusion of the spinal cord with fatty elements, the most common of which is an LMM. LMM is embryologically associated with tethered cord. ${ }^{5}$ Maternal dietary folic acid supplementation has been found to reduce the risk of neural tube defects among offspring. ${ }^{6}$ However, this has not been observed for $\mathrm{LMM}^{7}$ implying that the pathogenesis of LMM is embryologically different from that of other neural tube defects.

Lipomeningomyelocele are frequently associated with cutaneous and musculoskeletal abnormalities in addition to sensorimotor and urological dysfunction. ${ }^{8}$ Cutaneous lesions include subcutaneous lipomas, capillary hemangiomas, complex dimples and hypertrichosis. Musculoskeletal findings include scoliosis, unilateral or bilateral foot deformities such
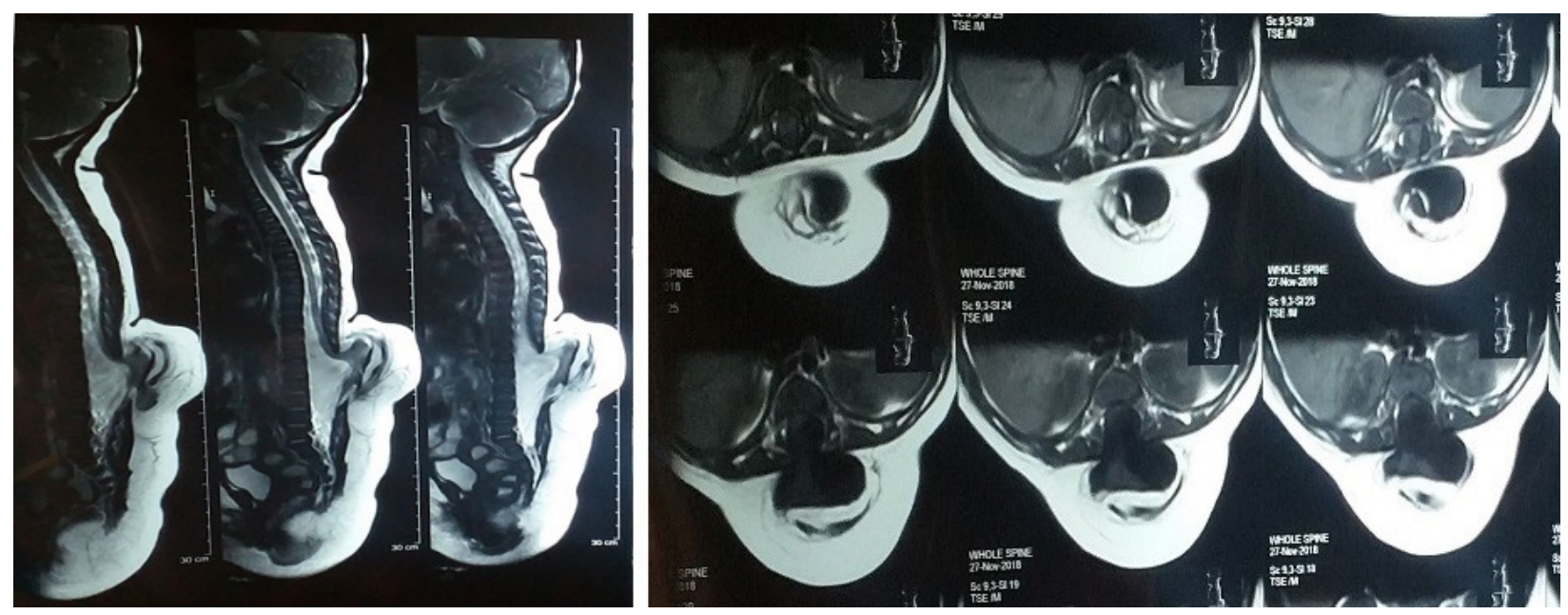

Figure 2. MRI picture of Lumbosacral LMMs, sagittal and axial views 

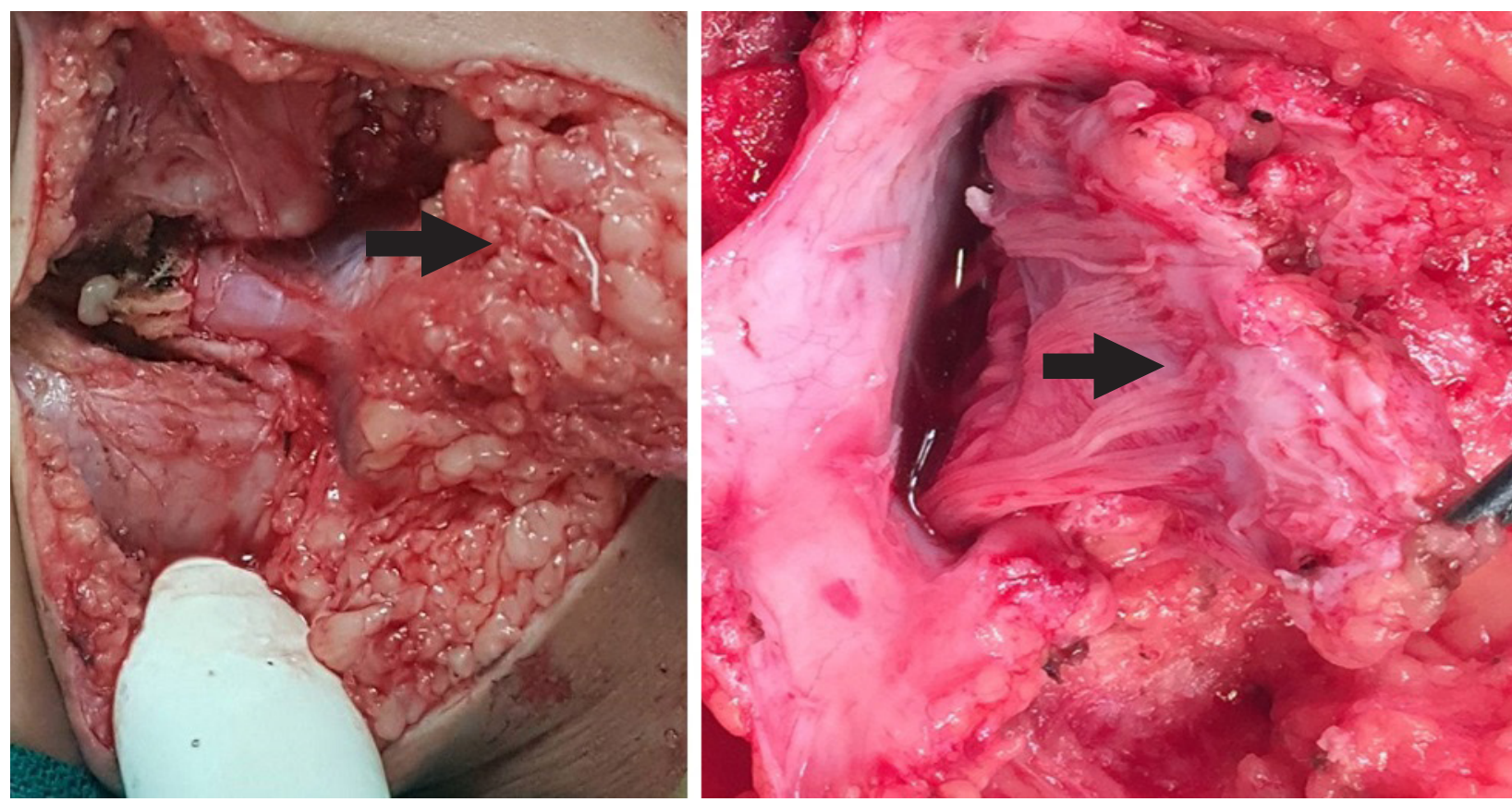

Figure 4. Intraoperative photograph before and after excision of lipomatous tissue. Lipomatous component attached to the dorsum of the cord (arrow). The origin of the nerve rootlets could be visualized from the cord (arrow)

as club foot, abnormal rotation or asymmetry of the foot or leg. Urologic dysfunction such as incontinence, frequency, urgency, and urinary tract infections are commonly associated. At birth neurological symptoms may be absent in nearly half of the cases. ${ }^{9}$ As the infant ages and axial growth occurs, the infant may experience progressive loss of neurological function. As axial growth continues, lower limb and sacral motor and sensory dysfunction such as radicular pain, leg spasticity, foot deformities and gait abnormalities can develop. ${ }^{10} \mathrm{LMMs}$ can become symptomatic from spinal stenosis secondary to mass effect as the lipomatous malformation increases mass over time. ${ }^{7}$ It can also be associated with other abnormalities such as genitourinary tract anomalies (4.1\%), split cord malformations (3.1\%), associated dermal sinuses $(3.1 \%)$, dermoid or epidermoid cysts $(3.1 \%)$, diastematomyelia $(3.1 \%)$, terminal hydromyelia (3.1\%), anal stenosis (1.0\%), and Down syndrome $(1.0 \%) .{ }^{10}$

A detailed MRI is the definitive imaging evaluation for LMMs. Plain radiographs or computed tomography imaging may be useful to assess for scoliosis and evaluate the spine's bony anatomy during preoperative planning.
Surgery is the mainstay of treatment. The lipomatous component is in close relation with the neural tissue, which may limit complete resection of the lipomatous component without causing neurological injury. ${ }^{11}$ Role of surgery before the onset of neurological symptoms is a debatable issue. Kulkerni et al shed light on the natural history, citing a 33\% risk of symptom deterioration with conservative management versus $46 \%$ for surgical treatment at nine year follow up. Outcomes after surgery for lipomyelomeningocele correlate with preoperative function of the patient. Spinal cord retethering following lipomyelomeningocele repair has been found to be between $10 \%$ and $20 \% .{ }^{12}$ Back pain, deterioration of lower extremity function, worsening of urological, and bowel function indicate retethering. It develops 3-8 years after the initial surgery. ${ }^{13}$

Pang et al suggested aggressive approach involving total or near total resection of lipoma, complete reconstruction of the neural placode, followed by expansile duraplasty, preferably using bovine pericardium. ${ }^{14}$ Using their technique, they showed no neurologic deterioration in $88.1 \%$ of patients over 20 years follow up, compared to $34.6 \%$ risk of progression over 10 years in patients with only partial resection .

Table 4. Post-operative functional outcome

\begin{tabular}{lcccc}
\hline \multicolumn{1}{c}{ Functions } & Total patients & Improvement & Deterioration & No change \\
\hline Motor funtions & 4 & 1 & - & 3 \\
Sensory funtions & 2 & - & 1 & 1 \\
Autonomic funtions & 4 & 1 & - & 3 \\
\hline
\end{tabular}


In the study by Mahapatra et al in 2007, 34 patients had motor symptoms, 15 had sensory symptoms and 24 had autonomic symptoms, five patients with motor symptoms improved and two deteriorated. Two patients with sensory symptoms improved and five patients with autonomic symptoms improved.

In our study, out of four patients with motor symptoms, one improved and three remained static. Two patients with sensory symptoms, one improved and one remained static and four patients with autonomic symptoms, only one improved (Table 4).

After careful evaluation, simple LMMs with symptoms or any LMMs with an associated sensorimotor deficit should be considered for possible surgical intervention. Caudal and dorsal spinal lipomas are typically more amenable to surgical treatment than the rest. Immediate postoperative complication rates range from $10-30 \%$ and include infection, CSF leak, or neurological deterioration. ${ }^{15}$ When surgery is elected, it is better to aggressively resect the lipoma along with reconstruction of the placode and large expansile duraplasty and close follow-up of patients with residual lipoma and undivided filum terminale to pick up early signs of neurological deterioration.

\section{CONCLUSION}

LMMs management remains a challenge. Due to the risk of worsening neurological, urological, and bowel function secondary to a tethered spinal cord, it continues to be important to identify this condition for timely intervention. Results of this study have shown that surgery for LMM is safe and if done with correct technique achieves its purpose of preventing neurological deterioration. It is very important to counsel and encourage the patients regarding early repair in diagnosed cases as the results of surgery in patients with established neurological insult are not as good as those in preoperatively asymptomatic patients.

\section{CONFLICT OF INTEREST}

None declared.

\section{REFERENCES}

1. Blount JP, Elton S. Spinal lipomas. Neurosurg Focus. 2001; 10:e3

2. Chapman PH. Congenital intraspinal lipomas: Anatomic considerations and surgical treatment. Childs brain . 1982;9:37-47

3. Pang D, Zovickian J, Wong ST et al. Surgical treatment of complex spinal cord lipomas. Childs Nerv Syst.2013;29:1485-13

4. Forrester MB, Merz RD. Descriptive epidemiology of lipolyelomeningocele, Hawaii, 1986-2001. Birth defects Res A Clin Mol Teratol. 2004; 70:953-6

5. Warder DE. Tethered cord syndrome and occult spinal dysraphism. Neurosurg Focus. 2001;10:e1

6. Frey $L$, Hauser WA. Epidemiology of neural tube defects. Epilepsia. 2003;44(Suppl 3):4-13

7. McNeely PD, Howes WJ. Ineffectiveness of dietary folic acid supplementation on the incidence of lipomyelomeningocele: Pathogenetic implications. J Neurosurg. 2004;100(2 Suppl):98-100

8. Muthukumar N . Congenital spinal lipomatous malformations: Part I - Classification . Acta Neurochir . 2009;151:179-88

9. Hertzler DA 2nd, DePowell JJ, Stevenson CB, Mangano FT. Tethered cord syndrome : a review of the literature from embryology to adult presentation.Neurosurg Focus . 2010;29:e1

10. Hoffman HJ, Taecholarn C, Hendrick EB, Humphreys RP. Management of lipomyelomeningoceles. Experience at the hospital for sick children, Toronto. J Neurosurg. 1985;62:1-8

11. Naidich TP, McLone DG, Mutluer S. A new understanding of dorsal dysraphism with lipoma (lipomyeloschisis): Radiologic evaluation and surgical correction. AJR Am J Roentgenol. 1983;140:1065-78

12. Pierre-Kahn A, Lacombe J, Pichon J, et al. Intraspinal lipomas with spina bifida. Prognosis and treatment in 73 cases. J Neurosurg. 1986;65:756-61.

13. Cochrane DD, Finley C, Kestle J, Steinbok P. The patterns of late deterioration in patients with transitional lipomyelomeningocele. Eur J Pediatr Surg. 2000;10(Suppl 1):13-7.

14. Pang D , Zovickian J , Wong ST et al. Surgical treatment of complex spinal cord lipomas. Childs Nerv Syst.2013;29:1485-13

15. Kanev PM, Lemire RJ, Loeser JD, Berger MS. Management and long term follow up review of children with lipomyelomeningocele, 1952-1987. J Neurosurg. 1990;73: 48-52 